\title{
Relato Tech Ladies: redes de colaboração entre mulheres na tecnologia.
}

\author{
Ana C. M. Souza' ${ }^{1}$, Izadora Perkoski ${ }^{2}$, Khalyandra Veiga ${ }^{4}$, Vanessa Romankiv ${ }^{3}$ \\ Programa de Pós-Graduação em Informática (PPGIa) - Pontifícia Universidade \\ Católica do Paraná (PUCPR) \\ Rua Imaculada Conceição 1155 - 80.215-901 - Curitiba - PR - Brasil
}

PPrograma de Pós-Graduação em Educação Especial (PPGEES) - Universidade Federal de São Carlos (UFSCar)

Rod. Washington Luís km 235 - 13565-905 - São Carlos - SP - Brasil

Programa de Pós-Graduação em Desgin Centrado no Usuário -

Universidade Positivo (UP)

Rua Professor. Pedro Viriato Parigot de Souza - 80740-050 - Curitiba - PR - Brasil

${ }^{4}$ Tech Ladies

Curitiba - PR - Brasil

ana.moises@ppgia.pucpr.br,$\frac{\{\text { izaperkoski, khalyandra, anessaromankiv\} }}{\text { @gmail.com }}$

Abstract. The discussion about gender stereotyping has been a concern for the future of women in the fields of science, technology, engineering and math (STEM). In order to change this scenario, many initiatives for women in technology are emerging. In this direction, this paper presents the objectives, structure and work carried out during the first year of Tech Ladies network, as an initiative that connects, teaches and empowers women in the area of technology.

Resumo. A discussão sobre estereótipos de gênero é uma preocupação para o futuro da mulher nas áreas da ciência, tecnologia, engenharia e matemática (STEM). Visando mudar esse cenário, muitas iniciativas para as mulheres na tecnologia estão surgindo. Nessa direção, este artigo apresenta os objetivos, a estrutura e o trabalho realizado durante o primeiro ano da rede Tech Ladies, como uma iniciativa que conecta, ensina e empodera mulheres na área da tecnologia.

\section{Introdução}

Recentemente o Fórum Econômico Mundial publicou o Relatório de Desigualdade Global de Gênero 2016, onde cita que o Brasil está 79- posição no que diz respeito a paridade econômica de gêneros nas áreas de acesso à Educação, Saúde e Sobrevivência, Oportunidade Econômica e Empoderamento Político [World Economic Forum 2016]. O relatório conclui que o progresso para equidade de gênero ocorre de forma lenta no contexto mundial. Com o progresso tecnológico a maioria dos postos de trabalhos com predominância feminina tende a se reduzir demandando assim urgência na adesão de mulheres nas áreas de ciência, tecnologia, engenharia e matemática (STEM).

Neste cenário, buscam-se meios de incentivar mulheres a ingressarem e permanecerem na tecnologia e alguns movimentos que vêm acontecendo ao longo dos 
anos. No Brasil, ainda de acordo com o estudo de [Nunes et al. 2016], surgiram 16 iniciativas desde 2005, criadas por universidades, entre elas destacam-se os projetos Meninas Digitais [Maciel e Bim 2016] e Emili@s [Bim 2016]. Essas iniciativas promovem palestras, oficinas, congressos e até mesmo blogs. Além da contribuição das universidades com projetos de extensão com este foco, as iniciativas privadas (organizações não governamentais, startups, comunidades e pessoas físicas) estão se organizando e se unindo. Um exemplo disso é o Mapa das Minas ${ }^{1}$ criado para listar todas essas iniciativas no Brasil.

Com intuito de continuar incentivando meninas a entrarem na área de TI, compartilhar conhecimentos adquiridos na profissão, colaborar com as diversas iniciativas existentes, promover oficinas, palestras, eventos, integrar universidades, espaços de coworkings e empresas, nasceu a rede apresentada neste artigo.

Este artigo está organizado da seguinte maneira: a Seção 2 apresenta a rede; na seção 3 são descritos os resultados atingidos pela rede até o momento; e a seção 4 conclui o artigo.

\section{Apresentação e Motivação}

A rede Tech Ladies foi criada a partir da percepção e vivência da fundadora a respeito da baixa participação e alto índice de desistência das mulheres na área de tecnologia, tanto no mercado de trabalho quanto em cursos acadêmicos. Essa percepção é confirmada por uma pesquisa relacionada à baixa participação de mulheres na área de TI que teve como foco entrevistas com alunas dos cursos de Sistemas de Informação e Engenharia da Computação [De Lima 2014]. Outra pesquisa em andamento, busca explicar o motivo da exclusão feminina [Castelini 2016] confrontando a masculinização da área e o imaginário estabelecido socialmente de que a mulher não é capaz, não pode ser aluna ou profissional da área da computação

Preocupada com todo esse contexto, a rede se apresenta como um espaço para troca de conhecimento, ascensão profíssional, desenvolvimento pessoal e valorização da mulher nas áreas de exatas.

\subsection{Objetivos}

É uma rede de empoderamento feminino na tecnologia visando incentivar, inspirar, conectar e imergir as meninas e mulheres no universo da tecnologia. Pretende-se, por meio da inovação tecnológica e empreendedorismo, aumentar a participação das mulheres no mercado tecnológico promovendo a equidade de gênero.

Atua na realização, colaboração e participação de iniciativas, projetos, oficinas, palestras e eventos. A rede apoia e conecta as diversas iniciativas distribuídas no território nacional com o objetivo de unir as mulheres da área de forma colaborativa. Articula projetos de aplicativos mobile, sistemas web, robôs e sensores com o objetivo de aprimorar os conhecimentos em novas tecnologias e permitir que as participantes coloquem em prática os conhecimentos adquiridos nas oficinas. As palestras

\footnotetext{
https://www.google.com/maps/d/viewer?mid=1PFfESBALPxGFuMPJNcTq-ZRT9lk\&hl=en US\&ll=$7.454682350012113 \% 2 \mathrm{C}-35.112382976562515 \& \mathrm{z}=8$
} 
promovidas abordam assuntos que agregam conhecimento tanto no aspecto técnico quanto humano. A participação e promoção de eventos permite divulgar e conectar a rede nos ecossistemas de inovação com objetivo de conhecer parceiros e oportunidades.

Para que a rede atinja os objetivos listados acima foram definidas as seguintes metas: a) aumentar em $20 \%$ as mulheres atuantes na rede por meio de 15 oficinas a serem realizadas durante o ano de 2017 todas elas propostas pelas integrantes da rede e parceiros; b) a cada oficina realizada e divulgada nos canais de comunicação da rede, nota-se que pelo menos uma nova mulher ou menina começa a participar da rede. Já temos parceria de local para esses eventos; c) além das oficinas está sendo planejado para o final do ano um evento de dois dias que contará com oficinas e palestras para engajamento de mais meninas e mulheres; d) para aumentar a participação de meninas e mulheres na área da tecnologia, nota-se que algumas integrantes da Tech Ladies, já estão conseguindo trabalhos como freelances. Isto se deve a conexão e networking que a rede está estabelecendo.

\subsection{Estrutura}

A estrutura da Tech Ladies é composta por embaixadoras, equipe técnica e integrantes. As embaixadoras são mulheres professoras e empresárias que desde o início da rede apoiam os trabalhos e são exemplos de superação e dedicação. A equipe técnica é formada por mulheres profissionais de diversas áreas, como marketing, psicologia, administração e computação, que organizam eventos, palestras e oficinas. As integrantes são mulheres e meninas que querem aprender mais sobre a área e que participam de eventos promovidos pela rede.

Dentro dessa estrutura é possível perceber diferentes perfis de acordo com objetivo e história de vida de cada integrante. Neste contexto, participam da rede:

- Mulheres atuantes na tecnologia, que trabalham com tecnologia da informação, web design, testes, engenharias, programação, gerentes de projetos, analista de negócio, ensino e diversas outras áreas.

- Mulheres e meninas que buscam uma área para iniciar sua vida profissional na tecnologia, normalmente são alunas do ensino médio que estão pretendendo ingressar numa das áreas de STEM e procura por orientação profissional e o que a mulher precisa enfrentar dentro da área.

- Mulheres que já desistiram de atuar na tecnologia e com o apoio da rede estão retornando e acreditando que elas podem trabalhar na área e serão reconhecidas.

Percebe-se que as integrantes da rede se sentem à vontade para compartilhar e aprender, estão entusiasmadas com a rede e procuram sempre participar dos eventos.

\section{Resultados do Projeto}


No decorrer do ano de 2016 e início de 2017 a rede participou de diversos eventos para divulgação das suas atividades: palestras, mentorias em hackathons ${ }^{2}$, eventos e oficinas. O primeiro dos eventos promovidos pela rede foi o lançamento da iniciativa ArduLadies, focada no ensino de eletrônica com Arduino ${ }^{3}$ para mulheres, incentivando a capacidade de realizar projetos por si mesmas - movimento maker ${ }^{4}$. Além disso, foram quatro palestras sobre introdução ao Arduino e apresentação da rede nos eventos: Paraná DevDay - SEBRAE, TechDay - EBANX, Charneira - PUCPR, Jornada de Atualização em Informática - UniCuritiba.

Depois disso, para divulgar a rede, foram reunidas mulheres inspiradoras em um evento onde 10 palestras foram ministradas sobre os seguintes temas: programação, design, negócios, jornalismo, inclusão das mulheres na tecnologia. Esse evento obteve 100 inscritas e 80 participantes e contou com o apoio da Universidade Positivo, TopTal, Agência Liderança Feminina, Just - Assistente Virtual, Rede Mulher Empreendedora (RME). As integrantes da rede estiveram presentes em quatro hackathons, sendo que em três deles com mentorias de desenvolvimento, design e negócios (Hackathon Paraná, Hackathon OAB, Hackathon Copel SENDI) e uma equipe que desenvolveu uma solução para durante o Hackathon SESI.

Uma outra iniciativa foi a Oficina Django Girls, que orientou o desenvolvimento de um blog no framework Django com Python. Foi realizada em parceria com a Aldeia Coworking, e contou com 7 tutoras da rede e tutores de outras comunidades. $\mathrm{O}$ evento contemplou 30 participantes, das quais $80 \%$ das mulheres não eram da área de TI, e gerou uma lista de espera de mais 90 pessoas. Também foi organizado o Dojô de Arduino com programação intuitiva por meio do Scratch for Arduino (S4A), evento realizado em conjunto com a Eletron e em parceria com O Penal coworking, contou com a participação de 10 meninas.

Por fim, a rede organizou também a oficina de empoderamento feminino, realizado em parceria com o Centro Europeu e Unistart, com o objetivo de inspirar as integrantes e mostrar que todas as mulheres possuem força, garra, inteligência e controle emocional por meio de técnicas de Coaching [Navarro 2015]. O evento teve um total de 13 participantes das 18 inscritas.

\section{Considerações Finais}

Este artigo apresentou detalhes sobre a rede, com a motivação para a sua criação, seus objetivos e os trabalhos realizados. Todo esse movimento está sendo realizado por diferentes perfis de mulheres: atuantes na tecnologia, as que buscam uma área para iniciar sua vida profissional e as que já desistiram de atuar na tecnologia e com o apoio

https://en.wikipedia.org/wiki/Hackathon

https://www.arduino.cc/

https://en.wikipedia.org/wiki/Maker_culture 
da rede estão retornando e acreditando que elas podem trabalhar na área e serão reconhecidas. Embora ainda sem dados sistemáticos, é possível observar preliminarmente alguns impactos da criação da rede no ecossistema local, promovendo diversidade e inclusão no mercado de tecnologia. A recepção das participantes parece ser bastante positiva, com uma procura crescente pelos eventos e oficinas promovidos pela rede e engajamento voluntário de cada vez mais mulheres. $\mathrm{O}$ envolvimento de profissionais, estudantes e interessadas pela área de tecnologia em iniciativas como essa rede permite que as mulheres criem relações seguras, de confiança e cooperação, em um ambiente motivador e positivo.

No futuro, espera-se que a rede seja capaz de fortalecer e ampliar a participação feminina no mercado de tecnologia de forma cada vez mais efetiva e ampla.

\section{Referencias}

Bim, S. A.; Amaral, M. A.; Kozievitch, N. P.; Emer, M. C. F. P.; Setti, M. O. G.; Pellison, L. A.; Merkle, L. E.. Divulgar para Atrair, Motivar para Manter. In: $10^{\circ}$ WIT - Women in Information Technology, 2016, Porto Alegre. Anais do XXXVI congresso da sociedade brasileira de computação: \#Computaçãoeinterdisciplinaridade. Porto Alegre: EDIPUCRS Editora Universitária da PUCRS, 2016. p. 2665 - 2669

Castelini, P.; Amaral, M. A.; Barbosa E., Silva, R. Women and the imaginary in Computer courses at UTFPR. In: XI JORNADAS LATINOAMERICANAS DE ESTUDOS SOCIAIS DA CIENCIA E DA TECNOLOGIA, ESOCITE 2016: ESOCITE 21 Anos: Trajetórias plurais entre passados e futuros, 2016.

De Lima, Alves Fabiane. Mulheres na Tecnociência: depoimentos e vivências de mulheres nos cursos de Computação da Universidade Tecnológica Federal do Paraná. Disponível em: http://repositorio.utfpr.edu.br:8080/jspui/bitstream/1/1007/1/CT_PPGTE_M_LIMA $\% 2 c \% 20$ Fabiane\%20Alve s\%20de_2014.pdf, March.

Nunes, M.A.S.N.; Louzada, C. S.; Salgueiro, E. M. ; Carvalho, B. T. A. ; Lima, P. S. ; Figueredo, R. M. C. T.; Mapeamento de iniciativas brasileiras que fomentam a entrada de mulheres na Computação . In: $10^{\circ}$ WIT, 2016, Porto Alegre. X Women in Information Technology. In: CSBC. Porto Alegre: SBC, 2016. v. 1. p. 2692-2696.

Maciel, C., Bim, S. A. Programa Meninas Digitais - ações para divulgar a Computação para meninas do ensino médio. In: Computer on the Beach, 2016, Florianópolis. Anais [do] Computer on the Beach, 2016. p. 327-336.

Navarro, R,: Poder do Coaching: Aumente seu nível. Aprenda. Supere. Conquiste, Instituto Coaching Financeiro e Editora Momentum, ISBN 978-85-66788-04-4, 2014.

World Economic Forum (2016); "The Global Gender Gap Report 2016, http://www3.weforum.org/docs/GGGR16/WEF_Global_Gender_Gap_Report_2016. pdf, March. 